Saudi Journal of Biomedical Research

Abbreviated Key Title: Saudi J Biomed Res ISSN 2518-3214 (Print) |ISSN 2518-3222 (Online)

\title{
"High- Sensitivity C-Reactive Protein Correlation with Angiographic Findings in Patients with Acute Coronary Artery Syndrome",
}

\author{
Dr. Greeshma B Kotain ${ }^{1}$, Dr. Shaheen B Shaikh ${ }^{2 *}$, Liliya S Joy ${ }^{3}$, Dr. Nivedita L Rao ${ }^{4}$, Dr. Prashanth R M ${ }^{5}$, Dr. Ismail H M \\ ${ }^{1}$ Assistant Professor, Department of Biochemistry, Yenepoya Medical College Hospital, Mangaluru, Karnataka, India \\ ${ }^{2}$ Associate Professor, Department of Biochemistry, Yenepoya Medical College Hospital, Mangaluru, Karnataka, India \\ ${ }^{3}$ Research Scholar, Department of Biochemistry, Yenepoya Medical College Hospital, Mangaluru, Karnataka, India \\ ${ }^{4}$ Professor, Department of Biochemistry, Yenepoya Medical College Hospital, Mangaluru, Karnataka, India \\ ${ }^{5}$ Assistant Professor, Department of Cardiology, Yenepoya Medical College Hospital, Mangaluru, Karnataka, India \\ ${ }^{6}$ Associate Professor, Department of Critical Care Medicine, Yenepoya Medical College Hospital, Mangaluru, Karnataka, India
}

DOI: $10.36348 /$ sjbr.2021.v06i04.001 | Received: 26.02.2021 | Accepted: 29.03.2021 | Published: 02.04 .2021

*Corresponding author: Dr. Shaheen B Shaikh

\section{Abstract}

Background: ACS is a major cause of mortality and morbidity in both developed and developing countries. HsCRP is an independent risk marker of cardiovascular disease. Objective: The aim of this study was to compare serum hsCRP levels and lipid profile and to correlate with angiographic findings. Materials and methods: This is a case control study, 70 patients with onset of chest pain and 70 sex matched controls were enrolled. Details of clinical examination, ECG, angiographic findings and laboratory findings like CK-MB, AST, LDH also collected. RESULTS: Among the cases, highest mean levels of hs-CRP, CK-MB and LDH were found in STEMI patients compared to other two groups. Among the 28 UA patients 21 were diabetic (75\%), in the case of STEMI it was 79\%, 19 out of 24, and in the case of NSTEMI 12 out $18(67 \%)$. Patients with SVD, had hs-CRP levels $<1-3 \mathrm{mg} / \mathrm{L}$ whereas most of the patients with TVD had elevated (>3 mg/L) hs-CRP level. Conclusion: The present study showed a positive correlation between hsCRP, dyslipidemia and angiographic findings in ACS. Hs-CRP seems to be a stronger predictor of cardio vascular events.

Key words: High sensitivity-reactive protein, acute coronary syndrome, lipid profile, CK-MB, triple vessel disease, dyslipidemia.

Copyright (C) 2021 The Author(s): This is an open-access article distributed under the terms of the Creative Commons Attribution 4.0 International License (CC BY-NC 4.0) which permits unrestricted use, distribution, and reproduction in any medium for non-commercial use provided the original author and source are credited.

\section{INTRODUCTION}

Cardiovascular disease (CVD) is a leading cause of morbidity and mortality good pharmacotherapy and interventional management $[1,2]$. ACS (acute coronary syndrome) refers to a spectrum of conditions compatible with acute myocardial ischemia and/or infarction that are usually due to an abrupt reduction in coronary blood flow, ACS is a combined term for unstable Angina (UA),ST Elevation Myocardial Ischemia (STEMI), Non-ST Elevation Myocardial Ischemia (NSTEMI) [3, 4].

ACS is a major cause of mortality and morbidity in India. There are some non-modifiable risk factors for Coronary heart disease (CHD) such as age, sex, race and family history of coronary heart disease. However, there are several risk factors that can be managed through lifestyle modification such as smoking, stress, hyperlipidemia, hypertension, diabetes mellitus, and obesity and sedentary lifestyle [5]. Of the various risk factors, stress and hyperlipidemia are considered to be the major risk factors of atherosclerosis [6]. High-sensitivity C-reactive protein (hsCRP) is proposed as an inflammatory marker since decades for cardiovascular events in future [7]. Inflammation has a key role in ACS evolution. Inflammatory marker high sensitivity $\mathrm{C}$-reactive protein (hsCRP) predicts ACS risk either by correlation with ACS extent or as an marker of inflammatory event that leads to plaque rupture $[8,9]$. The aim of this study was to compare serum hsCRP levels and lipid profile and to correlate with angiographic findings in a tertiary care hospital in Mangalore

\section{MATERIALS AND METHODS}

This is a case control study conducted among 70 patients who have been admitted in the cardiology critical care unit Yenepoya hospital Mangalore with onset of chest pain. Patients within the age group of 3060 were included in this study. Based on clinical history, 
the results of ECG, plasma cardiac markers, and stress test testing, patients were diagnosed by physicians as UA, STEMI and NSTEMI. This study also included age and sex matched 70 controls selected from the outpatient department, those who came for regular health checkups, without CAD which was assessed by history and clinical examination.

Informed consent was taken from both cases and controls after explaining the procedure. Details of smoking habits, life style and exercise pattern were elicited from the patients, and details of clinical examination, ECG, angiographic findings and laboratory findings such as conventional cardiac markers like CK-MB, AST, LDH also collected. Patients CKD, sepsis, recent or ongoing infection or fever, Chronic inflammatory systemic disorders such as RA, SLE, Angina of secondary etiology, Recent surgery, Thyroid disorders, Aortic valve disease, Obstructive hypertrophic cardiomyopathy were excluded from study.

Sample Processing and Analysis-5ml blood collected in plain vials (without any anticoagulant) for the estimating Lipid profile (Total cholesterol, triglycerides, and high density lipoprotein cholesterol) and serum high sensitivity C-reactive protein (hsCRP). HsCRP was measured by latex enhanced immune turbidimetric assay and carried out in auto analyzer AGAPPE diagnostics by using Agappe CRP ultra-kit according to the instructions of the manufacturer. Fasting Lipid profile was estimated by using VITROS 5600 Integrated System VITROS 250 Chemistry System from USA.

\section{STATISTICAL ANALYSIS}

The data was analyzed SPSS Version 13.0. Values were expressed as mean \pm standard deviation. Comparisons between the groups were done using chi square test and student's unpaired t test. A p $<0.05$ was considered statistically significant.

\section{RESULTS}

A total number of 70 ACS patients 70 healthy individuals as controls were included in this study, out of which 28 UA, 24 STEMI, 18 NSTEMI. The mean age in the control group was $46 \pm 10.26$ years and in the patient group $41 \pm 18.22$ yrs, $42 \pm 11.23$ yrs and $45 \pm 11.24$ yrs for UA, STEMI and NSTEMI respectively. It has been shown that male gender was predominant in all the ACS groups (47 out of 70). Total cholesterol, TG, LDL and blood pressure levels were significantly higher in UA, STEMI and NSTEMI compared to controls. HDL cholesterol level was significantly decreased in all the ACS groups compared to controls. Among the 28 UA patients 21 were diabetic $(75 \%)$, in the case of STEMI it was $79 \%, 19$ out of 24 , and in the case of NSTEMI 12 out $18(67 \%)$. Number of smokers in each group was 11,12,9 in UA, STEMI and NSTEMI respectively.

Comparison of hsCRP and cardiac enzyme levels in both controls and cases are depicted in table no 2.The mean levels of hs-CRP $(\mathrm{p}<0.05)$, CK-MB $(p<0.05)$ and AST $(p=0.03)$ were significantly higher in cases when compared to controls. There was no significant difference in the mean levels of $\mathrm{LDH}$ between cases and controls $\mathrm{p}=0.18(\mathrm{p}<0.05)$. Among the cases, highest mean levels of hs-CRP, CK-MB and LDH were found in STEMI patients compared to other two groups. Mean AST level was less in UA group compared to other groups. Nearly two-thirds of the patients with STEMI had hs- CRP levels above 3mg/l as compared to only half with UA/ NSTEMI. In comparison with lipid profile v/s hsCRP, TC, LDL and TG were tending to increase in all the three groups. There was no such significant difference among the three ACS groups.

Majority of the patients with SVD-single vessel disease, had hs-CRP levels $<1-3 \mathrm{mg} / \mathrm{L}$ whereas most of the patients with TVD- triple vessel disease had elevated $(>3 \mathrm{mg} / \mathrm{L})$ hs-CRP levels $(\mathrm{p}<0.001)$ depicted in fig no-1.

Table-1: Frequency of risk factors among study population

\begin{tabular}{|c|c|c|c|c|}
\hline \multirow[t]{2}{*}{ RISK FACTORS } & \multirow{2}{*}{$\begin{array}{l}\text { CONTROLS } \\
(\mathbf{n}=70)\end{array}$} & \multicolumn{3}{|l|}{$\operatorname{ACS}(n=70)$} \\
\hline & & UA( $(n=28)$ & $\begin{array}{l}\begin{array}{l}\text { STEMI } \\
(\mathbf{n}=24)\end{array} \\
\end{array}$ & $\begin{array}{l}\text { NSTEMI } \\
(n=18)\end{array}$ \\
\hline Age (yrs) & $46 \pm 10.26$ & $41 \pm 18.22$ & $42 \pm 11.23$ & $45 \pm 11.24$ \\
\hline Sex-M/F & $47 / 23$ & $19 / 9$ & $16 / 8$ & $12 / 6$ \\
\hline $\begin{array}{l}\text { Total Cho } \\
(\mathrm{mg} / \mathrm{dl})\end{array}$ & $138 \pm 25.23$ & $215 \pm 60.45$ & $240 \pm 54.69$ & $219 \pm 38.92$ \\
\hline $\begin{array}{l}\text { Triglycerides } \\
(\mathrm{mg} / \mathrm{dl})\end{array}$ & $110 \pm 72.92$ & $172 \pm 68.22$ & $220 \pm 74.92$ & $210 \pm 43.46$ \\
\hline $\begin{array}{l}\text { High Density Lipoprotein } \\
(\mathrm{mg} / \mathrm{dl})\end{array}$ & $42.6 \pm 20.36$ & $38.2 \pm 19.19$ & $32 \pm 19.48$ & $39 \pm 9.32$ \\
\hline $\begin{array}{l}\text { Low Density Lipoprotein } \\
(\mathrm{mg} / \mathrm{dl})\end{array}$ & $90 \pm 34.67$ & $170 \pm 40.55$ & $148 \pm 45.99$ & $187 \pm 58.79$ \\
\hline
\end{tabular}


Table-2: Hs-CRP comparison between cases and controls in Unstable Angina (UA)

\begin{tabular}{|c|c|c|c|}
\hline Cardiac marker & $\begin{array}{c}\text { Unstable Angina(UA) } \\
(\mathbf{n = 8})\end{array}$ & $\begin{array}{c}\text { CONTROLS } \\
(\mathbf{n = 7 0})\end{array}$ & P value \\
\hline $\begin{array}{c}\mathrm{hs}-\mathrm{CRP} \\
\mathrm{mg} / \mathrm{L}\end{array}$ & $4.30 \pm 0.57$ & $0.71 \pm 0.55$ & 0.03 \\
\hline
\end{tabular}

$* \mathrm{p}<0.05$ is considered as significant.

Table-3: Hs-CRP comparison between cases and controls in ST Elevated MI (STEMI)

\begin{tabular}{|c|c|c|c|}
\hline Cardiac marker & $\begin{array}{c}\text { ST Elevated MI } \\
(\mathbf{n = 2 4})\end{array}$ & $\begin{array}{c}\text { CONTROLS } \\
(\mathbf{n = 7 0})\end{array}$ & P value \\
\hline $\begin{array}{c}\text { hs-CRP } \\
\mathrm{mg} / \mathrm{L}\end{array}$ & $6.11 \pm 0.46$ & $0.71 \pm 0.55$ & 0.08 \\
\hline \multicolumn{2}{|c|}{$* \mathrm{p}<0.05$ is considered as significant. }
\end{tabular}

Table-4: Hs-CRP comparison between cases and controls in Non ST Elevated MI (NSTEMI)

\begin{tabular}{|c|c|c|c|}
\hline $\begin{array}{c}\text { Cardiac } \\
\text { marker }\end{array}$ & $\begin{array}{l}\text { Non ST Elevated MI. (NSTEMI) } \\
(\mathbf{n = 1 8})\end{array}$ & $\begin{array}{c}\text { CONTROLS } \\
(\mathbf{n}=\mathbf{7 0})\end{array}$ & $\begin{array}{c}\text { P } \\
\text { value }\end{array}$ \\
\hline $\begin{array}{c}\mathrm{hs}-\mathrm{CRP} \\
\mathrm{mg} / \mathrm{L}\end{array}$ & $5.23 \pm 0.84$ & $0.71 \pm 0.55$ & 0.03 \\
\hline
\end{tabular}

$* \mathrm{p}<0.05$ is considered as significant.

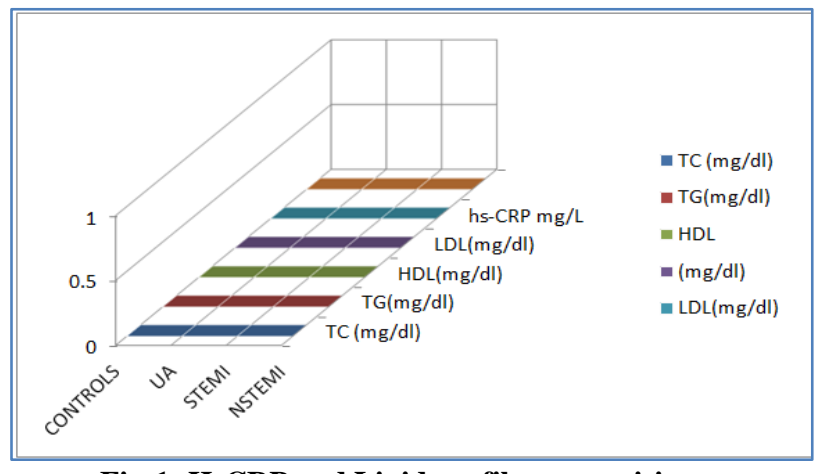

Fig-1: HsCRP and Lipid profile comparision

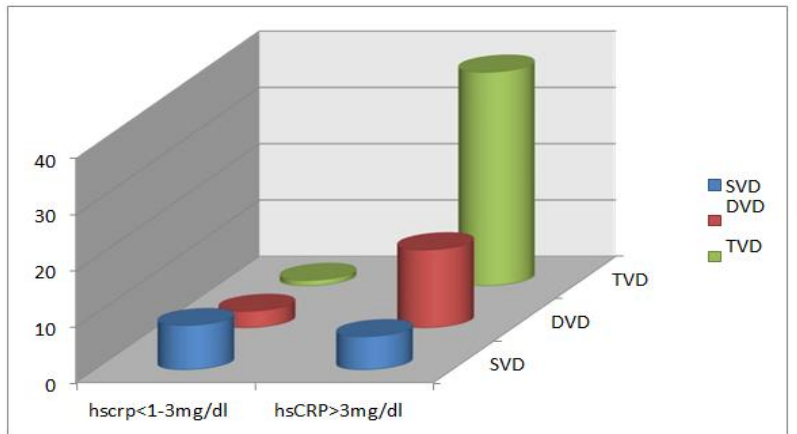

Fig-2: Levels of hsCRP in correlation with angiographic findings

\section{DISCUSSION}

The term acute coronary syndrome (ACS) refers to any group of clinical symptoms compatible with acute myocardial ischemia and covers the spectrum of clinical conditions ranging from unstable angina (UA) to non-ST-segment elevation myocardial infarction (NSTEMI) to ST-segment elevation myocardial infarction (STEMI).

UA and NSTEMI are closely related conditions, their pathophysiologic origins and clinical presentations are similar, but they differ in severity. A diagnosis of NSTEMI can be made when the ischemia is sufficiently severe to cause myocardial damage that result in the release of a biomarker of myocardial necrosis into the circulation like cardiac-specific troponin $\mathrm{T}$ or I, or CK-MB. In contrast, the patient is considered to have experienced UA if no such biomarker can be detected in the bloodstream hours after the initial onset of ischemic chest pain. Myocardial infarctions or stroke occur in people without hyperlipidemia. High risk assessment approaches are being explored to facilitate early and accurate identification of individuals at risk of having ACS. High-sensitive C-reactive protein (hs-CRP) has emerged as the most important $\mathrm{CV}$ risk marker since atherosclerosis is an inflammatory process.

Risk factors such as hypertension, diabetes, smoking and lack of exercise were found in this study population. A total number of 52 patients out of 70 were diabetic, most of them were hypertensive and among the male population 32 were smokers. Females were found to have higher hs-CRP levels as compared to males in our study. Several previous studies have shown similar results of hs-CRP levels higher in women in healthy populations [10].

Mechanisms explaining Hs-CRP influence on vascular vulnerability directly are enhanced expression of adhesive molecules, reduced nitric oxide, increased expression of endothelial PAI-1 and altered LDLuptake by macrophages [11]. Estimation of hsCRP helps to recognize patients who are at risk and may need medical treatment. The hs-CRP test clearly adds to the predictive value. Previous studies have provided the facts that inflammation plays a major role in the occurrence of CVD $[12,13]$. 
Some degree of information is existing about hs-CRP levels and their association with CV risk factors in Indian studies [14]. Therefore our study provides important insights in to this aspect which is eminently pertinent to day-to-day clinical practice. The patients with STEMI are known to have higher peak hs- CRP levels as compared to those with UA/NSTEMI. Our results are in accord with that of the studies done by Krintus et al. [15] and Sheikh et al. [16]. Study done by Brunetti [17] et al. showed that hsCRP concentrations showed a different release curve with Q-wave AMI in comparison with non Q- wave AMI and patients with UA. Comparable results were obtained in the study also.

Dyslipidemia (Increased total cholesterol, triglycerides \& LDL along with decreased HDL) is evident in this study. Chronic inflammatory process and dyslipidemia plays a significant role in the formation of atheromatous lesions, causing occlusion of arterial lumens. Haseeb khan [18] et al. reported that reduction in serum cholesterol does not prevent the risk of ACS.

The present study showed a significant correlation between the extent of CAD and hs-CRP levels, similar to several other previous studies. Study done by Zairis et al. reported that hs-CRP concentration correlated with the stenosis complexity in patients with acute coronary syndrome [19] Nyandak [20] et al. reported a major association between the hs-CRP levels and the extent of CAD as well as the angiographic stenosis score. The results reports that higher hs-CRP level also reflect increased disease burden.

\section{CONCLUSION}

In conclusion, the present study showed a positive correlation between hsCRP and dyslipidemia in ACS events in all the 3 groups. As inflammation plays a key role in the initiation and propagation of ACS events, inflammatory marker hsCRP can be proposed as diagnostic tool along with conventional marker such as cardiac troponins. In terms of clinical application, hsCRP seems to be a stronger predictor of cardio vascular events than LDL cholesterol and it can be suggested a marker for better prognosis of ACS.

\section{Limitations of the study}

The study population and study duration was less, effect of statin therapy with hsCRP level was not accounted and we couldn't evaluate the relationship between acute stress and hsCRP.

\section{REFERENCES}

1. Gupta, S., Gupta, V. K., Gupta, R., Arora, S., \& Gupta, V. (2012). Demographic profile and prevalence of risk factors and their correlation with STEMI, NSTEMI and premature CAD in documented CAD patients. Journal of Preventive Cardiology, 1(4), 164-172.

2. Pletcher, M. J., Tice, J. A., \& Pignone, M. (2004).
Use of coronary calcification scores to predict coronary heart disease. Jama, 291(15), 1831-1831.

3. Xavier, D., Pais, P., Devereaux, P. J., Xie, C., Prabhakaran, D., Reddy, K. S., \& Yusuf, S. (2008). Treatment and outcomes of acute coronary syndromes in India (CREATE): a prospective analysis of registry data. The Lancet, 371(9622), 1435-1442.

4. Braunwald, E., Isselbacher, K. J., Wilson, J. D., Martin, J. B., Kasper, D., Hauser, S. L., \& Longo, D. L. (2001). Harrison's Principles of Internal Medicine, 14th.

5. Gupta, R., Guptha, S., Sharma, K. K., Gupta, A., \& Deedwania, P. (2012). Regional variations in cardiovascular risk factors in India: India heart watch. World journal of cardiology, 4(4), 112.

6. James, C. (2013). Risk factors for coronary artery diseases: a study among patients with ischemic heart disease in Kerala. Heart India, 1(1), 7.

7. Ben-Yehuda, O. (2007). High-sensitivity Creactive protein in every chart? The use of biomarkers in individual patients. Journal of the American College of Cardiology, 49(21), 2139. 2141.

8. Kumar, A., \& Cannon, C. P. (2009). Acute coronary syndromes: diagnosis and management, part I. In Mayo Clinic Proceedings (Vol. 84, No. 10, pp. 917-938). Elsevier.

9. Imran, A., Achyut, S. (2014). Vascular Inflammation and Angiographic Severity of Coronary Artery Disease in Young Asian Indians Journal of cardiovascular disease research, 4(3), 112-114.

10. McConnell, J. P., Branum, E. L., Ballman, K. V., Lagerstedt, S. A., Katzmann, J. A., \& Jaffe, A. S. (2002). Gender differences in C-reactive protein concentrations-confirmation with two sensitive methods. Clinical Chemistry and Laboratory Medicine (CCLM), 40(1), 56-59.

11. Pearson, T. A., Mensah, G. A., Alexander, R. W., Anderson, J. L., Cannon III, R. O., Criqui, M., ... \& Vinicor, F. (2003). Markers of inflammation and cardiovascular disease: application to clinical and public health practice: a statement for healthcare professionals from the Centers for Disease Control and Prevention and the American Heart Association. Circulation, 107(3), 499-511.

12. Hak, A. E., Stehouwer, C. D., Bots, M. L., Polderman, K. H., Schalkwijk, C. G., Westendorp, I. C., ... \& Witteman, J. C. (1999). Associations of C-reactive protein with measures of obesity, insulin resistance, and subclinical atherosclerosis in healthy, middle-aged women. Arteriosclerosis, thrombosis, and vascular biology, 19(8), 19861991.

13. Ridker, P. M., Rifai, N., Pfeffer, M. A., Sacks, F. M., Moye, L. A., Goldman, S., \& Braunwald, E. (1998). Inflammation, pravastatin, and the risk of coronary events after myocardial infarction in patients with average cholesterol 
levels. Circulation, 98(9), 839-844.

14. Lagrand, W. K., Visser, C. A., Hermens, W. T., Niessen, H. W., Verheugt, F. W., Wolbink, G. J., \& Hack, C. E. (1999). C-reactive protein as a cardiovascular risk factor: more than an epiphenomenon?. Circulation, 100(1), 96-102.

15. Krintus, M., Kozinski, M., Stefanska, A., Sawicki, M., Obonska, K., Fabiszak, T., \& Sypniewska, G. (2012). Value of C-reactive protein as a risk factor for acute coronary syndrome: a comparison with apolipoprotein concentrations and lipid profile. Mediators of Inflammation, 2012.

16. Sheikh, A. S., Yahya, S., Sheikh, N. S., \& Sheikh, A. A. (2012). C-reactive protein as a predictor of adverse outcome in patients with acute coronary syndrome. Heart views: the official journal of the Gulf Heart Association, 13(1), 7.

17. Brunetti, N. D., Troccoli, R., Correale, M., luigi Pellegrino, P., \& Di Biase, M. (2006). C-reactive protein in patients with acute coronary syndrome: correlation with diagnosis, myocardial damage, ejection fraction and angiographic findings. International journal of cardiology, 109(2), 248-256.

18. Khan, H. A., Alhomida, A. S., \& Sobki, S. H. (2013). Lipid profile of patients with acute myocardial infarction and its correlation with systemic inflammation. Biomarker insights, 8, BMI-S11015.

19. Zairis, M. N., Papadaki, O. A., Manousakis, S. J., Thoma, M. A., Beldekos, D. J., Olympios, C. D., ... \& Foussas, S. G. (2002). C-reactive protein and multiple complex coronary artery plaques in patients with primary unstable angina. Atherosclerosis, 164(2), 355-359.

20. Nyandak, T., Gogna, A., Bansal, S., \& Deb, M. (2007). High sensitive C-reactive protein (hs-CRP) and its correlation with angiographic severity of coronary artery disease (CAD). JIACM, 8(3), 21721. 